\title{
The cutoff point of clinical chronic obstructive pulmonary disease questionnaire for more symptomatic patients
}

\author{
Yong Suk Jo ${ }^{1}$, Sangshin Park ${ }^{2,3}$, Deog Kyeom Kim ${ }^{4}$, Chul-Gyu Yoo ${ }^{1}$ and Chang-Hoon Lee ${ }^{1 *}$
}

\begin{abstract}
Background: An adequate threshold for the Clinical Chronic Obstructive Pulmonary Disease (COPD) Questionnaire (CCQ) defining more symptomatic COPD patients has not been determined. We aimed to determine the efficacy of the CCQ and the appropriate CCQ threshold for more symptomatic COPD patients.

Methods: COPD patients aged $>40$ years who smoked/had smoked $\geq 10$ packs/year were prospectively enrolled over 1 year from three South Korean hospitals $(n=126)$. Correlations between the CCQ and St. George's Respiratory Questionnaire (SGRQ), COPD Assessment Test (CAT), the modified Medical Round Council (mMRC) scale, lung function, and exercise capacity were evaluated. "More symptomatic patients" were those with an SGRQ score $\geq 25$. Area under the receiver operating curve and classification and regression tree analyses were performed to determine the CCQ threshold equivalent to an SGRQ score $\geq 25$.

Results: The CCQ significantly correlated with the SGRQ, CAT, and mMRC scale $(r=0.76,0.69$, and 0.53 , respectively). A CCQ cutoff of 1.4 predicted an SGRQ score of 25 better than others. A CCQ score of 1.4 was a significant determinant of an SGRQ score $\geq 25$ even after adjusting for potential confounders.

Conclusions: The CCQ was correlated with other symptom indicators, lung function, and exercise capacity. A CCQ cutoff of 1.4 agreed better than CCQ cutoff of 1.0, suggested by guideline, and this cutoff value may identify more symptomatic COPD patients well.
\end{abstract}

Trial registration: ClinicalTrials.gov Identifier: NCT02527486. Date of registration: December 19, 2014, retrospectively registered.

Keywords: Chronic Obstructive Pulmonary Disease, Correlation study, Health related quality of life, Clinical Questionnaires

\section{Background}

Chronic obstructive pulmonary disease (COPD), characterized by persistent and progressive airflow limitation, is one of the major causes of morbidity and mortality worldwide, and its prevalence is increasing. COPD was previously regarded as a disease mainly characterized by breathlessness, but recently it has been reported that

\footnotetext{
* Correspondence: kauri670@empal.com

'Division of Pulmonary and Critical Care Medicine, Department of Internal Medicine, Seoul National University Hospital, 101 Daehak-Ro Jongno-Gu, Seoul 03080, Republic of Korea

Full list of author information is available at the end of the article
}

COPD has multiple symptomatic effects on healthrelated quality of life (HRQOL) [1]. The severity of airflow limitation alone is not strongly correlated with HRQOL in COPD patients [2]; therefore, comprehensive methods to evaluate the COPD-specific health status are needed.

Since 2011, Global Initiative for Chronic Obstructive Lung Disease (GOLD) adopted St. George's Respiratory Questionnaire (SGRQ) as a new assessment tool for COPD patients considering their current respiratory symptoms and future risk of exacerbation. Currently, GOLD emphasizes HRQOL more than dyspnea alone and divides patients into more symptomatic (SGRQ $\geq 25)$ and 
less symptomatic (SGRQ < 25) patients based on previous clinical trials of long-acting bronchodilators [3-5].

SGRQ is the most widely used and valid tool to evaluate the health status of COPD patients [6] and is composed of 50 items with 76 weighted responses. The SGRQ scoring method is a bit difficult considering the amount of items and weighted responses required, and many COPD patients may find it difficult to complete without any help [7]. Thus, the COPD Assessment Test (CAT) was developed to compensate for the complexity of SGRQ [8, 9], and many studies which have evaluated the distribution of patients of GOLD grading classification according to the tool used to assess symptoms, found a different proportion of patients in each category using CAT score $\geq 10$. With this background, GOLD recommended that the equivalent point of CAT for SGRQ of 25 is 10 [8-12].

Clinical COPD Questionnaire (CCQ), which has a good correlation with SGRQ [13, 14], is also thought to be a good instrument for assessing health status in COPD patients and is simple to use [13]. However, although studies have reported that a CCQ score range of $1.0-1.5$ is consistent with an SGRQ score of 25 [14], until now, a clear CCQ cutoff point that is equivalent to an SGRQ score of 25 has not been determined. Furthermore, to date, the CCQ has not been sufficiently validated for evaluating health status in COPD patients in Asia [15].

Therefore, the present study aimed (i) to assess whether the CCQ correlates well with other health status measures, lung function, and exercise capacity in Korean COPD patients, and (ii) to determine the CCQ cutoff point that corresponds well with the SGRQ cutoff point of 25 , considered the standard representing more symptomatic patients.

\section{Methods}

\section{Study design and participants}

The Seoul National University Airway Registry is a prospective observational cohort study that enrolls patients with chronic airway disease, including COPD.(ClinicalTrials.gov Identifier: NCT02527486). Among the participants in the cohort, patients aged 40 years or more who were diagnosed as having COPD between April 2013 and December 2015 at Seoul National University Hospital, a tertiary care hospital, and between March 2014 and December 2015 at Boramae Medical center, a municipal hospital, and Seoul National University Bundang Hospital, were included in our study. A COPD case was defined as a current or former smoker ( $\geq 10$ packs/year) with chronic respiratory symptoms who had a post-bronchodilator forced expiratory volume in $1 \mathrm{~s}\left(\mathrm{FEV}_{1}\right)$ to forced vital capacity ratio $<0.7$. Participants who were not assessed either by SGRQ, the CAT, or the CCQ at the baseline visit were excluded. All patients signed the informed consent form to participate in this observational cohort. This study was approved by the Institutional Review Board (IRB) of Seoul National University Hospital (IRB no. 1602-122-743).

For COPD patients, a previous history of symptoms, exposure to smoking and biomass smoke, experiencing exacerbation, and comorbidities were evaluated at baseline. Pulmonary function tests including spirometry and lung volume measurements were performed at least annually. Spirometry was performed by standardized equipment, and lung volume was measured following the American Thoracic Society/European Respiratory Society guidelines $[16,17]$. Spirometry was repeated at least three times to verify the reproducibility and validity, and assessments of the pulmonary function test results were performed using computer programs and reviewed by highly qualified physicians. The spirometric reference value was calculated by Morris's predictive equation [18, 19].

Acute exacerbations were evaluated based on selfreported symptom aggravation requiring modification of current treatment. Severe exacerbation was defined as an acute exacerbation event requiring a visit to the emergency room or hospitalization, and moderate exacerbation was defined as an acute exacerbation requiring a visit to an outpatient clinic and treatment with short-term systemic corticosteroids or antibiotics. Our definition of exacerbation was mainly based on a modified respiratory questionnaire from the Epidemiology Standardization Project questionnaire [20].

\section{Clinical assessment instruments}

The SGRQ total score ranges from 0 to 100 where 100 indicates the worst quality of life, and its minimum clinically important difference (MCID) value is 4 units [21]. The CAT total score ranges from 0 to 40 , and 2.0 units is suggested as its MCID value [22]. The modified British Medical Research Council (mMRC) questionnaire total score ranges from 0 to 4 where 4 means most severe dyspnea, and an mMRC score $\geq 2$ is used as a cutoff point for dividing patients with less dyspnea from those with more dyspnea [23]. The 6-min walk test was performed to measure exercise capacity and assessed according to the American Thoracic Society guidelines, and its MCID value is $30 \mathrm{~m}$ [24].

The CCQ consists of 10 questions distributed in three domains (symptom, functional state, and mental state) assessed by a seven-point scale from 0 to 6 , which indicate the best (asymptomatic and no limitation) and the worst conditions (extremely symptomatic and limited), respectively [13]. The CCQ total score is calculated by summing the scores of the 10 questions and dividing it by the number of items [25]. The Korean version of the CCQ was used in the present study [26].

\section{Statistical analysis}

Descriptive data are expressed as mean \pm standard deviation or number (\%) unless otherwise specified. To evaluate the 
correlation between questionnaires (CCQ vs. SGRQ, CCQ vs. CAT, and CCQ vs. mMRC) and between CCQ and lung function indexes $\left(\mathrm{FEV}_{1} \%\right.$ and 6-min walk distance), we used Pearson correlation analyses. The degree of agreement between two indexes is expressed as the correlation coefficient, $r$, where a positive value means positive correlation and the higher the value, the stronger the correlation.

We used several CCQ cutoff scores based on an SGRQ score of 25 and a CAT score of 10, to indicate more symptomatic patients according to guidelines. We also applied a CCQ score that is equivalent to an SGRQ score of 20, which is better than suggesting an SGRQ score of 25 for a CAT score of 10 [27]. To determine which CCQ cutoff score was the most equivalent to an SGRQ score of 25, an area under the receiver operating curve (AUROC) analysis was performed. A classification and regression tree (CART) analysis, a type of decision tree methodology for the identification of mutually exclusive subgroups of atrisk persons who share common characteristics related to particular health-related behavior, was also performed. Then, the Cohen's kappa coefficient was calculated to compare the degree of agreement between the CCQ cutoff points and an SGRQ score of 25.

All analyses were two-sided and performed at a significance level of 0.05 unless otherwise noted. A $P$-value <.05 was considered statistically significant. All analyses were carried out using STATA version 13.1 (StataCorp, College Station, Texas, USA).

\section{Results}

\section{Patient characteristics}

Among 278 patients enrolled in the prospective cohort, we excluded 42 patients based on their spirometry and smoking pack/year and 110 patients whose health status indexes were not recorded (Fig. 1). Consequently, 126 patients aged 40 years or older who answered the questionnaires and agreed to regular follow-up at an outpatient clinic were finally enrolled.

The mean SGRQ, CAT, and CCQ scores were 38.04 \pm $18.18,17.76 \pm 7.68$, and $2.03 \pm 0.94$, respectively. Among 126 patients, $46(36.51 \%)$ patients recalled that they experienced at least one acute exacerbation event 1 year before enrollment and 17 (13.49\%) patients recalled more than two acute exacerbation events during the past year. The mean frequency of severe and moderate exacerbation was $1.4 \pm 0.52$ and $2.05 \pm 2.01$ events per year, respectively (Table 1). As can be seen in Figs. 2a and b, the CCQ values corresponding to the SGRQ scores of 25,20 , and a CAT score of 10 were $1.2,1.0$, and 0.7 , respectively.

\section{Correlation between the CCQ and other health status questionnaires, lung function, and exercise capacity} The CCQ significantly correlated well with SGRQ, the CAT, and the mMRC $(r=0.76,0.69$, and 0.53 , respectively)

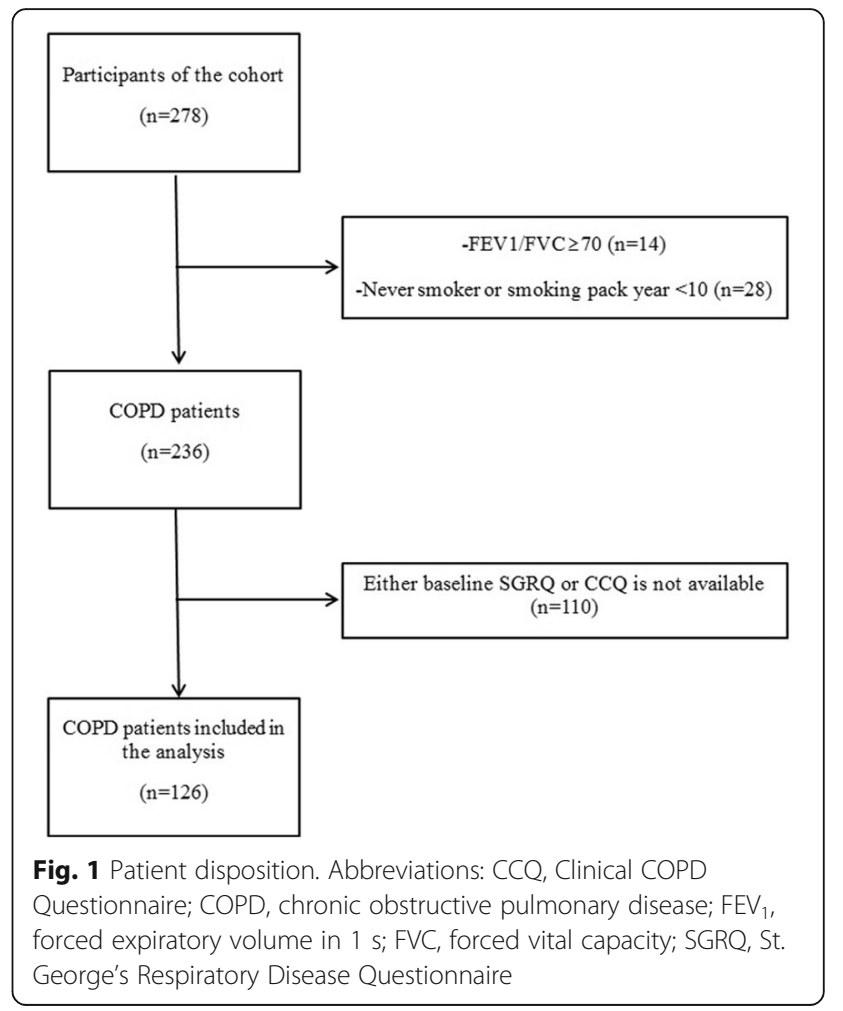

(Fig 2). The CCQ showed a significant negative correlation with $\mathrm{FEV}_{1}$ and 6-min walk distance $(\mathrm{r}=-0.40$ and -0.42 , respectively) (Fig. 3).

CCQ cutoff point to identify more symptomatic patients A cutoff point of 1.4 showed the highest AUROC for identifying more symptomatic patients with SGRQ $\geq 25$ (AUROC $=0.605,0.633,0.681,0.762$, and 0.711 for the CCQ cutoff points of $0.7,1.0,1.2,1.4$, and 1.6, respectively) (Fig. 4). The categorization based on the CCQ cutoff point of 1.4 showed the highest agreement with the SGRQ 25-based categorization (CCQ cutoff point $=0.7$ : agreement rate $=75.61 \%$ and $\mathrm{\kappa}$ value $=0.27$; CCQ cutoff point $=1$ : agreement rate $=76.42 \%$ and $\mathrm{\kappa}$ value $=0.33$; CCQ cutoff point $=1.4$ : agreement rate $=82.11 \%$ and $\mathrm{k}$ value $=0.56$ ) (Table 2). Even when adjusting for age, sex, body mass index, and $F E V_{1}$, a CCQ score $\geq 1.4$ was the good determinant of an SGRQ score $\geq 25$ in the CART analysis (relative hazard risk, 1.23) (Fig. 5).

\section{Discussion}

This study demonstrated that the CCQ is well correlated with other health status measurements including SGRQ, pulmonary function, and exercise capacity in Korean COPD patients. In our study, based on AUROC and CART analyses, the CCQ cutoff point that best corresponds to an SGRQ score of 25 was 1.4, which showed a better agreement rate and a higher classification power compared with other cutoff points. 
Table 1 Baseline characteristics of patients

\begin{tabular}{|c|c|}
\hline Characteristics & $N=126$ \\
\hline Age (years) & $68.83 \pm 7.23$ \\
\hline Sex: Male & $123(97.62)$ \\
\hline $\mathrm{BMI}\left(\mathrm{kg} / \mathrm{m}^{2}\right)$ & $22.97 \pm 3.27$ \\
\hline \multicolumn{2}{|l|}{ Smoking status } \\
\hline Ex-smoker & $88(69.84)$ \\
\hline Current smoker & $38(30.16)$ \\
\hline Packs per/year & $\begin{array}{l}54.47 \pm \\
64.46\end{array}$ \\
\hline \multicolumn{2}{|l|}{ History of exacerbations in the past year } \\
\hline Unplanned visit to an outpatient clinic (no./year) & $2.05 \pm 2.01$ \\
\hline $\begin{array}{l}\text { Unplanned visit to an emergency department or } \\
\text { hospital admission (no./year) }\end{array}$ & $1.4 \pm 0.52$ \\
\hline$\geq 2$ events in the past year $(n, \%)$ & $17(13.49)$ \\
\hline FEV1 (L) & $1.65 \pm 0.53$ \\
\hline FEV1 (\%) & $\begin{array}{l}65.35 \pm \\
19.42\end{array}$ \\
\hline FVC (L) & $3.59 \pm 0.79$ \\
\hline FVC (\%) & $\begin{array}{l}97.15 \pm \\
17.10\end{array}$ \\
\hline FEV1/FVC & $\begin{array}{l}45.95 \pm \\
11.55\end{array}$ \\
\hline \multicolumn{2}{|l|}{ GOLD stage } \\
\hline 1 (FEV1 > 80\% predicted) & $23(18.25)$ \\
\hline 2 (FEV1 50\%-79\% predicted) & $76(60.32)$ \\
\hline 3 (FEV1 30\%-49\% predicted) & $23(18.25)$ \\
\hline 4 (FEV1 < 30\% predicted) & $4(3.17)$ \\
\hline SGRQ score & $\begin{array}{l}38.04 \pm \\
18.18\end{array}$ \\
\hline CAT score & $17.76 \pm 7.68$ \\
\hline mMRC dyspnea score & $1.44 \pm 0.92$ \\
\hline CCQ score & $2.03 \pm 0.94$ \\
\hline $6 \mathrm{MWT}(\mathrm{m})$ & $\begin{array}{l}444.39 \pm \\
103.85\end{array}$ \\
\hline
\end{tabular}

Data are presented as mean \pm standard deviation or $\mathrm{n}(\%)$ Abbreviations: BMI body mass index, CAT Chronic Obstructive Pulmonary Disease Assessment Test, CCQ Clinical Chronic Obstructive Pulmonary Disease Questionnaire, FEV1 forced expiratory volume in $1 \mathrm{~s}, F V C$ forced vital capacity, GOLD Global Initiative for Chronic Obstructive Lung Disease, $m M R C$ modified Medical Research Council, SGRQ St. George's Respiratory Disease Questionnaire, 6MWT 6-min walk test

GOLD recommends a comprehensive approach to assess and adequately manage symptoms in COPD patients and proposes the $\mathrm{mMRC}, \mathrm{CAT}$, and $\mathrm{CCQ}$ as interchangeable instruments for evaluation of health status. However, despite the potential clinical importance, the CCQ has not been widely used in clinical practice because there is no known precise CCQ cutoff point that correlates with an SGRQ cutoff point of 25 (considered the standard marker of more symptomatic patients) and also CAT has been preferred than CCQ because CAT is more widely

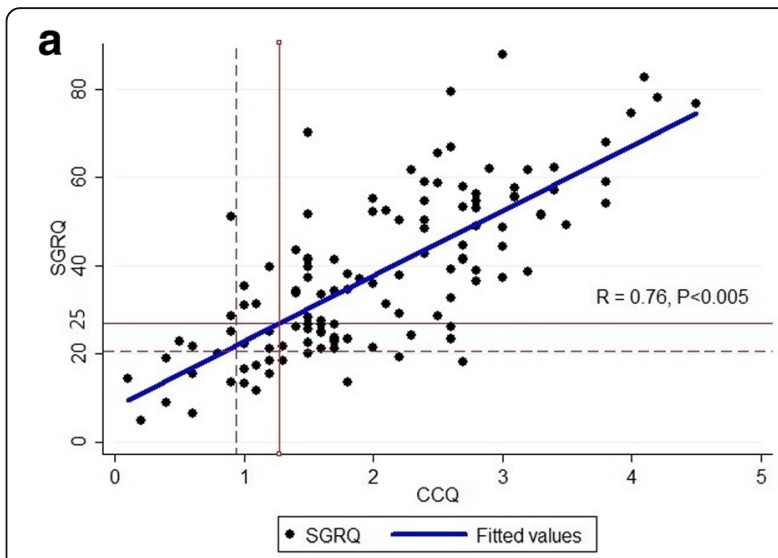

b
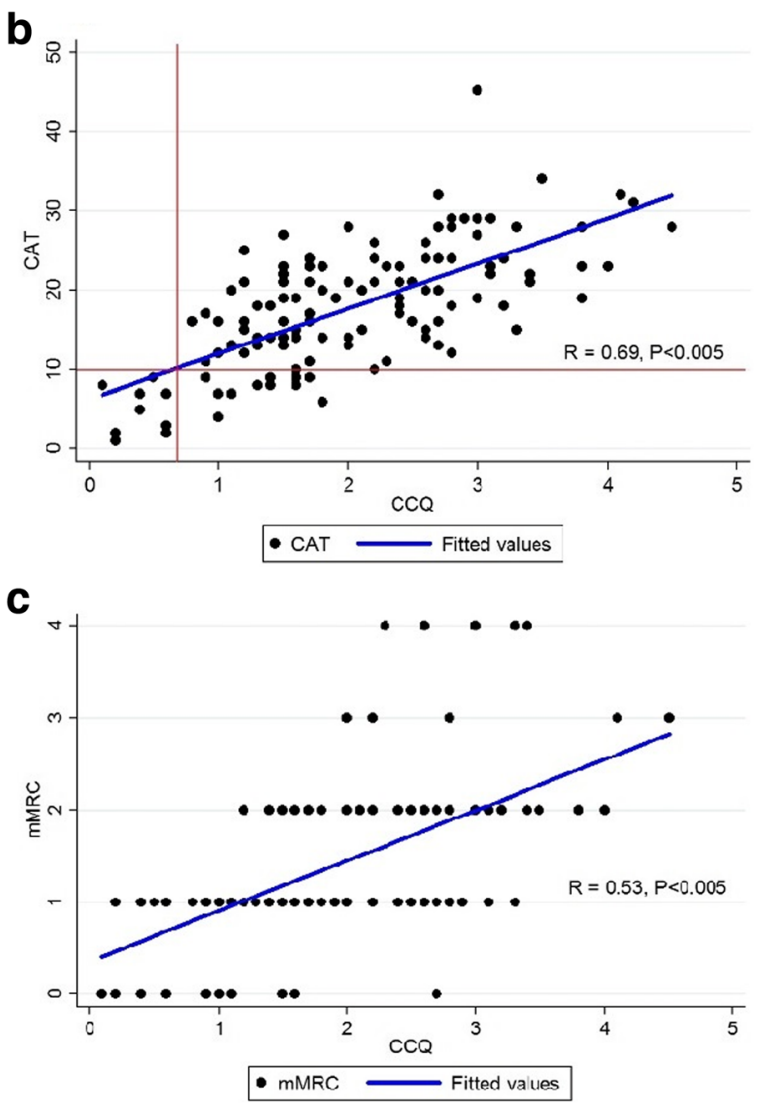

Fig. 2 Correlation between the CCQ and the (a) SGRQ, (b) CAT, and (c) mMRC. a, b CCQ value for SGRQ score of 25, 20 and for CAT score of 10 determined by an area under the receiver operating curve (AUROC) analysis

implemented and recommended by GOLD. GOLD guidelines recently set a CCQ score range of $1.0-1.5$ as being equivalent to an SGRQ score of 25 [23], and recent studies suggest that the MCID value for the CCQ is approximately $0.4[28,29]$. However, this wide range seems to be impractical for use in the clinical setting. In addition, GOLD tends to focus more on the CAT rather than the CCQ.

Based on the findings of the present study, we suggest that a CCQ cutoff point of 1.4 is appropriate for dividing 

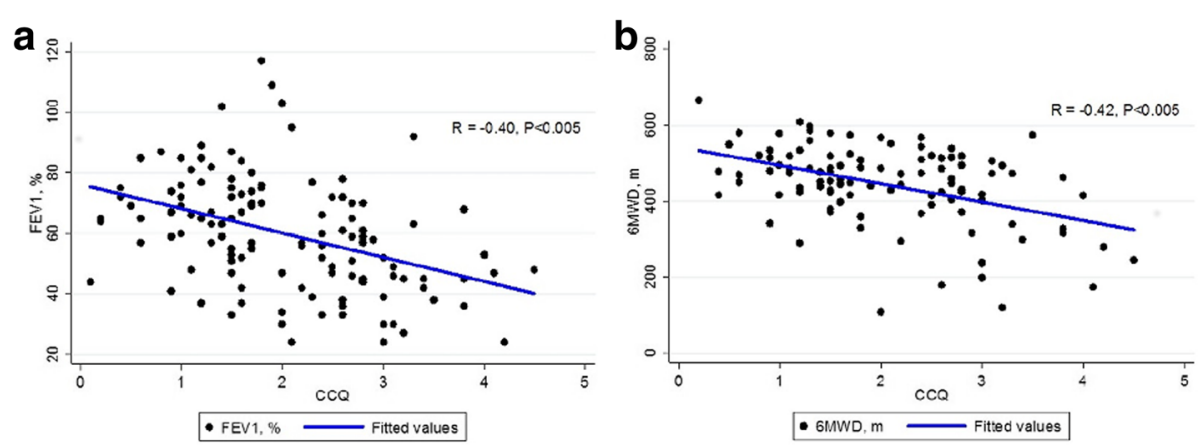

Fig. 3 Correlation between the CCQ and the (a) FEV $1 \%$ and (b) 6MWD. Abbreviations: CCQ, Clinical Chronic Obstructive Pulmonary Disease Questionnaire; $\mathrm{FEV}_{1}$, forced expiratory volume in $1 \mathrm{~s} ; 6 \mathrm{MWT}$, 6-min walk test

COPD patients into more symptomatic and less symptomatic patients. This was based on two analyses. First, the AUROC value for a CCQ cutoff point of 1.4 was the highest for agreement with an SGRQ score of 25. Second, a CCQ cutoff point of 1.4 was the best value to distinguish between an SGRQ score $\geq 25$ and $<25$ in the CART analysis. Consequently, a CCQ cutoff point of 1.4 was more concordant with an SGRQ cutoff point of 25, when compared to a CCQ cutoff point of 1.0. A low agreement was found with the SGRQ score of 25 , when analysis was performed based on the CCQ cutoff point of 0.7 , which corresponds to the CAT score of 10 , based on CAT instead of SGRQ. This is in line with our previous report, which states that scores higher than a CAT score of 10 , say 15, are more useful for assessment of the severity of symptoms [30].

SGRQ is the most comprehensive disease-specific health status measure for COPD patients. However, because it is composed of 50 items, it is complicated for

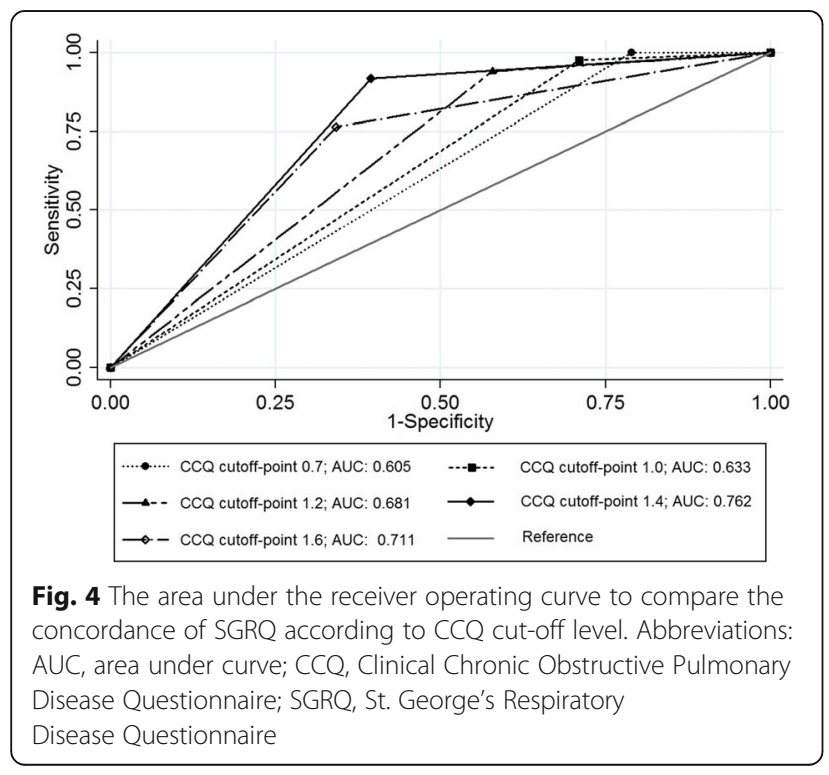

older COPD patients to answer without any help, and it takes a relatively long time to complete [7]. The CCQ is thought to be an alternative to SGRQ and consists of only 10 questions assessed by a seven-point scale from 0 to 6. Because the CCQ is a simple tool, it takes about 2 min to complete, and subjects require no specific help to complete it [13]. Along with its simplicity, the CCQ is a comprehensive tool to evaluate the health status in COPD patients because it has three domains (symptoms, functional state, and mental state), which means that the CCQ has psychometric properties that make it more useful [13]. CAT, one of the symptom and HRQOL measurement proposed by GOLD, is one-dimensional tool, while CCQ is similar to SGRQ, which is the most comprehensive tool. Further, CCQ is more simple and easy to use than SGRQ. Since it contains the description for each score, patients can sassily respond to the questions by themselves. In this aspect, the present study is focused on CCQ.

Table 2 Agreement between SGRQ and the CCQ based on the new GOLD classification of the CCQ cutoff value

\begin{tabular}{lll}
\hline & CCQ $<1$ & CCQ $\geq 1$ \\
SGRQ $<25$ & 11 & 27 \\
SGRQ $\geq 25$ & 2 & 83
\end{tabular}

Agreement: 76.42\%; kappa value, 0.33

$$
\text { CCQ }<1.4
$$

SGRQ $<25$

$$
23
$$

$S G R Q \geq 25$

7

78

Agreement: 82.11\%; kappa value, 0.56

$$
\text { CCQ }<0.7
$$

$\mathrm{SGRQ}<25$

8

30

$S G R Q \geq 25$

0

85

Agreement: 75.61\%; kappa value, 0.27

Abbreviations: CCQ Clinical Chronic Obstructive Pulmonary Disease Questionnaire, GOLD Global Initiative for Chronic Obstructive Lung Disease, SGRQ St. George's Respiratory Disease Questionnaire 


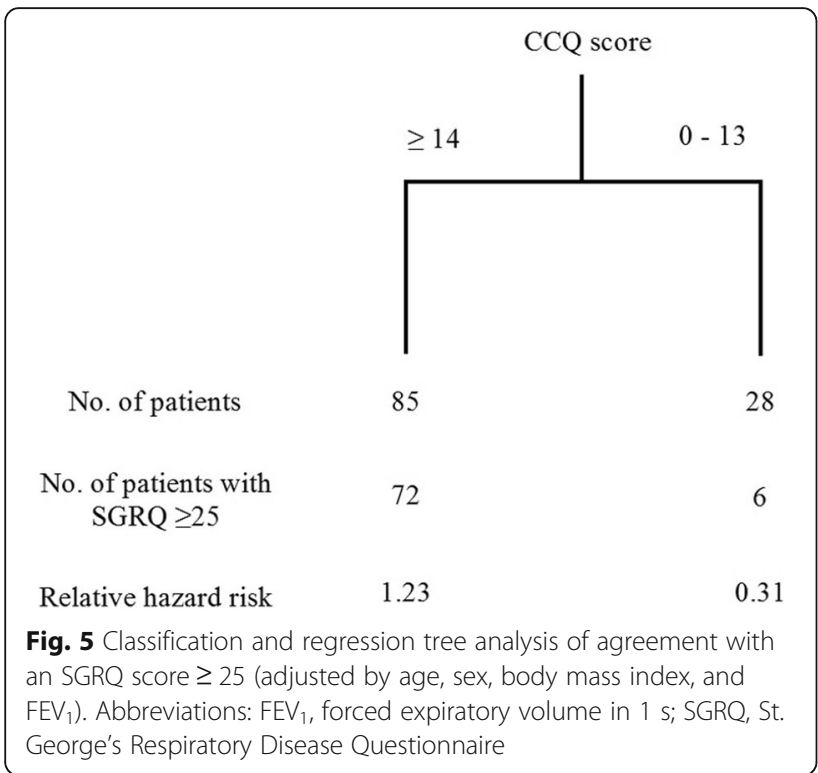

This study confirmed the clinical efficacy of the CCQ for evaluating the health status of COPD patients. The CCQ correlates well with other health status measures, lung function, and exercise capacity. In addition, recent studies have suggested that an upward revised CAT as a symptom threshold could reflect health status more accurately than the existing CAT cutoff point $(\geq 10)$, which was previously regarded as a surrogate of the SGRQ [30-32]. Furthermore, our study determined a new and clear CCQ threshold for categorizing COPD patients as more or less symptomatic.

The present study has several limitations to consider. First, we conducted a cross-sectional analysis and did not investigate the predictive value of CCQ for lung function decline or future exacerbation risk. Second, although the CCQ consists of three domains (symptoms, functional state, and mental state), we did not record the three subcategories separately, but rather evaluated the CCQ as a whole. Third, only small number of women were included because of the low prevalence of female smokers, therefore there may be a limitations in external validity. Fourth, the gold standard of cutoff points to measure symptoms in COPD remained open for discussion. Thus, we also showed results of applying the CAT score of 10 as a standard for the symptom criteria. Lastly, the suggested CCQ cutoff point of 1.4 needs to be externally validated.

\section{Conclusions}

The CCQ showed significant clinical value for assessing the health status of patients with COPD and showed good correlation with other questionnaires including SGRQ and the CAT as well as lung function and exercise capacity. Although the gold standard tool for assessing the severity of symptom in COPD patients may still be debated, CCQ threshold 1.4 showed a better agreement with SGRQ threshold of 25 , suggested by GOLD.

\section{Abbreviations}

6MWT: 6-min walk test; BMI: Body mass index;i CAT: Chronic Obstructive Pulmonary Disease Assessment Test; CCQ: Clinical Chronic Obstructive Pulmonary Disease Questionnaire; FEV 1 : Forced expiratory volume in $1 \mathrm{~s}$; FVC: Forced vital capacity; GOLD: Global Initiative for Chronic Obstructive Lung Disease; mMRC: Modified Medical Research Council; SGRQ: St. George's Respiratory Disease Questionnaire

\section{Funding}

The authors received no funding for this study.

\section{Authors' contributions}

YSJ and CHL made substantial contributions to the conception and design of the study, as well as to the acquisition of the data, drafting of the manuscript, and revising the study. YSJ drafted and revised the manuscript, and CHL verified its intellectual merit. We appreciate Professor SSP at the Center for International Health Research, Medical School of Brown University, for the statistical review. DKK, SSP, CGY and CHL read and approved the final manuscript. The decision to submit the report for publication was made by $\mathrm{CHL}$.

\section{Ethics approval and consent to participate}

This study was approved by the Institutional Review Board (IRB) of Seoul National University Hospital (IRB no. 1602-122-743).

\section{Consent for publication}

Not applicable.

\section{Competing interests}

The authors declare that they have no competing interests.

\section{Publisher's Note}

Springer Nature remains neutral with regard to jurisdictional claims in published maps and institutional affiliations.

\section{Author details}

${ }^{1}$ Division of Pulmonary and Critical Care Medicine, Department of Internal Medicine, Seoul National University Hospital, 101 Daehak-Ro Jongno-Gu, Seoul 03080, Republic of Korea. ${ }^{2}$ Center for International Health Research, Rhode Island Hospital, The Warren Alpert Medical School of Brown University, Providence, RI 02903, USA. ${ }^{3}$ Department of Pediatrics, The Warren Alpert Medical School of Brown University, Providence, RI 02903, USA.

${ }^{4}$ Division of Pulmonary and Critical Care Medicine, Department of Internal Medicine, Seoul Metropolitan Government-Seoul National University Boramae Medical Center, Seoul, Republic of Korea.

Received: 4 April 2017 Accepted: 15 February 2018

Published online: 27 February 2018

\section{Reference}

1. Jones PW. Health status measurement in chronic obstructive pulmonary disease. Thorax. 2001;56(11):880-7.

2. Ioanna T, Kocks J, Tzanakis N, Siafakas N, van der Molen T. Factors that influence disease-specific quality of life or health status in patients with COPD: a systematic review and meta-analysis of Pearson correlations. Prim Care Respir J. 2011;20(3):257-68.

3. Vincken W, Van Noord J, Greefhorst A, Bantje TA, Kesten S, Korducki L, Cornelissen P. Improved health outcomes in patients with COPD during 1 yr's treatment with tiotropium. Eur Respir J. 2002;19(2):209-16.

4. Jones PW, Singh D, Bateman ED, Agusti A, Lamarca R, de Miquel G, Segarra R, Caracta C, Gil EG. Efficacy and safety of twice-daily aclidinium bromide in COPD patients: the ATTAIN study. Eur Respir J. 2012;40(4):830-6. 
5. Kerwin EM, D'Urzo AD, Gelb AF, Lakkis H, Gil EG, Caracta CF. Efficacy and safety of a 12-week treatment with twice-daily aclidinium bromide in COPD patients (ACCORD COPD I). COPD: J Chron Obstruct Pulmon Dis. 2012;9(2):90-101.

6. Jones PW, Quirk FH, Baveystock CM, Littlejohns P. A self-complete measure of health status for chronic airflow limitation: the St. George's respiratory questionnaire. Am Rev Respir Dis. 1992;145(6):1321-7.

7. Ferrer M, Alonso J, Prieto L, Plaza V, Monsó E, Marrades R, Aguar M, Khalaf A, Antó J. Validity and reliability of the St George's respiratory questionnaire after adaptation to a different language and culture: the Spanish example. Eur Respir J. 1996:9(6):1160-6.

8. Jones PW, Brusselle G, Dal Negro RW, Ferrer M, Kardos P, Levy ML, Perez T, Cataluña JS, van der Molen T, Adamek L. Properties of the COPD assessment test in a cross-sectional European study. Eur Respir J. 2011;38(1):29-35.

9. Jones P, Harding G, Berry P, Wiklund I, Chen W, Leidy NK. Development and first validation of the COPD assessment test. Eur Respir J. 2009:34(3):648-54.

10. Rieger-Reyes C, García-Tirado FJ, Rubio-Galán FJ, Marín-Trigo JM. Classification of chronic obstructive pulmonary disease severity according to the new Global initiative for chronic obstructive lung disease 2011 guidelines: COPD assessment test versus modified Medical Research Council scale. Archivos de Bronconeumología (English Edition). 2014;50(4):129-34.

11. Jones PW, Nadeau G, Small M, Adamek L. Characteristics of a COPD population categorised using the GOLD framework by health status and exacerbations. Respir Med. 2014;108(1):129-35.

12. Han J, Dai L, Zhong N, Young D. Breathlessness or health status in chronic obstructive pulmonary disease: the impact of different definitions. COPD: Chron Obstruct Pulmon Dis. 2015;12(2):115-25.

13. Van der Molen T, Willemse BW, Schokker S, Ten Hacken NH, Postma DS, Juniper EF. Development, validity and responsiveness of the clinical COPD questionnaire. Health Qual Life Outcomes. 2003;1(1):1.

14. Sundh J, Ställberg B, Lisspers K, Kämpe M, Janson C, Montgomery S. Comparison of the COPD assessment test (CAT) and the clinical COPD questionnaire (CCQ) in a clinical population. COPD: J Chron Obstruct Pulmon Dis. 2016;13(1):57-65.

15. Lin W-C, Huang T-Y, Liu C-Y, Yeh M-L, Yu C-H, Hwang S-L. Validation of the clinical COPD questionnaire in Taiwan. COPD: J Chron Obstruct Pulmon Dis. 2016:13(3):360-6.

16. American Thoracic Society. Single-breath carbon monoxide diffusing capacity (transfer factor). Recommendations for a standard technique-1995 update. Am J Respir Crit Care Med. 1995;152(6 Pt 1):2185-98.

17. Wanger J, Clausen J, Coates A, Pedersen O, Brusasco V, Burgos F, Casaburi R, Crapo R, Enright P, Van Der Grinten C. Standardisation of the measurement of lung volumes. Eur Respir J. 2005;26(3):511.

18. Morris JF, Koski A, Johnson LC. Spirometric standards for healthy nonsmoking adults 1-3. Am Rev Respir Dis. 1971;103(1):57-67.

19. LEE CH, LEE JY, JANG EJ, PARK KY, HAN HW. New predictive equations for spirometric reference values and comparison with Morris equation in a Korean population. Respirology. 2008;13(3):365-71.

20. Ferris BG. Epidemiology standardization project (American Thoracic Society). Am Rev Respir Dis. 1978;118(6 Pt 2):1.

21. Mahler DA, Wells CK. Evaluation of clinical methods for rating dyspnea. CHEST J. 1988;93(3):580-6.

22. Kon SS, Canavan JL, Jones SE, Nolan CM, Clark AL, Dickson MJ, Haselden BM, Polkey MI, Man WD. Minimum clinically important difference for the COPD assessment test: a prospective analysis. Lancet Respir Med. 2014;2(3):195-203.

23. Global strategy for the diagnosis, management, and prevention of chronic obstructive pulmonary disease. http://www.goldcopd.org/. Accesse 18 Nov 2017.

24. Laboratories ACoPSfCPF. ATS statement: quidelines for the six-minute walk test. Am J Respir Crit Care Med. 2002;166(1):111.

25. Canavan JL, Dilaver D, Clark AL, Jones SE, Nolan CM, Kon SS, Man WDC. Clinical COPD questionnaire in patients with chronic respiratory disease. Respirology. 2014;19(7):1006-12.

26. CCQ Korean version. Available from: http://ccq.nl/?wpsc-product=ccqkorean-korean-24h-version. Accesse 18 Nov 2017.

27. Tsiligianni IG, Alma HJ, de Jong C, Jelusic D, Wittmann M, Schuler M, Schultz K, Kollen BJ, van der Molen T, Kocks JW. Investigating sensitivity, specificity, and area under the curve of the clinical COPD questionnaire, COPD assessment test, and modified Medical Research Council scale according to GOLD using St George's respiratory questionnaire cutoff 25 (and 20) as reference. Int J Chron Obstruct Pulmon Dis. 2016;11:1045-52.

28. Kon SS, Dilaver D, Mittal M, Nolan CM, Clark AL, Canavan JL, Jones SE, Polkey MI, Man WD. The clinical COPD questionnaire: response to pulmonary rehabilitation and minimal clinically important difference. Thorax. 2014;69(9):793-8.

29. Kocks JW, Tuinenga M, Uil S, Van den Berg J, Stahl E, Van der Molen T. Health status measurement in COPD: the minimal clinically important difference of the clinical COPD questionnaire. Respir Res. 2006;7(62):1465-993.

30. Lee C-H, Lee J, Park YS, Lee S-M, Yim J-J, Kim YW, Han SK, Yoo C-G. Chronic obstructive pulmonary disease (COPD) assessment test scores corresponding to modified Medical Research Council grades among COPD patients. Korean J Intern Med. 2015;30(5):629.

31. Pillai AP, Turner AM, Stockley RA. Global initiative for chronic obstructive lung disease 2011 symptom/risk assessment in a1-antitrypsin deficiency. CHEST J. 2013;144(4):1152-62.

32. Karloh M, Mayer AF, Maurici R, Pizzichini MM, Jones PW, Pizzichini E. The COPD assessment test: what do we know so far?: a systematic review and meta-analysis about clinical outcomes prediction and classification of patients into GOLD stages. CHEST J. 2016;149(2):413-25.

\section{Submit your next manuscript to BioMed Central and we will help you at every step:}

- We accept pre-submission inquiries

- Our selector tool helps you to find the most relevant journal

- We provide round the clock customer support

- Convenient online submission

- Thorough peer review

- Inclusion in PubMed and all major indexing services

- Maximum visibility for your research

Submit your manuscript at www.biomedcentral.com/submit
Biomed Central 